\title{
BMJ Global Health Hubris, humility and humanity: expanding evidence approaches for improving and sustaining community health programmes
}

\author{
Asha S George, ${ }^{1}$ Amnesty E LeFevre, ${ }^{2,3}$ Meike Schleiff, ${ }^{3}$ Arielle Mancuso, ${ }^{3}$ \\ Emma Sacks, ${ }^{3,4}$ Eric Sarriot ${ }^{4,5}$
}

To cite: George AS, LeFevre AE, Schleiff M, et al. Hubris, humility and humanity: expanding evidence approaches for improving and sustaining community health programmes. BMJ Glob Health 2018:3:e000811. doi:10.1136/ bmjgh-2018-000811

Handling editor Stephanie M Topp

Received 5 March 2018

Revised 3 May 2018

Accepted 3 May 2018

Check for updates

${ }^{1}$ School of Public Health, University of the Western Cape, Cape Town, South Africa ${ }^{2}$ Division of Epidemiology and Biostatistics, School of Public Health and Family Medicine, University of Cape Town, Cape Town, South Africa

${ }^{3}$ Johns Hopkins University, Baltimore, Maryland, USA ${ }^{4}$ Maternal and Child Surviva Program, USAID, Washington, District of Columbia, USA ${ }^{5}$ Save the Children, Washington, District of Columbia, USA

Correspondence to Professor Asha S George; asgeorge@uwc.ac.za

\section{ABSTRACT}

Community-based approaches are a critical foundation for many health outcomes, including reproductive, maternal, newborn and child health (RMNCH). Evidence is a vital part of strengthening that foundation, but largely focuses on the technical content of what must be done, rather than on how disparate community actors continuously interpret, implement and adapt interventions in dynamic and varied community health systems. We argue that efforts to strengthen evidence for community programmes must guard against the hubris of relying on a single approach or hierarchy of evidence for the range of research questions that arise when sustaining community programmes at scale. Moving forward we need a broader evidence agenda that better addresses the implementation realities influencing the scale and sustainability of community programmes and the partnerships underpinning them if future gains in community RMNCH are to be realised. This will require humility in understanding communities as social systems, the complexity of the interventions they engage with and the heterogeneity of evidence needs that address the implementation challenges faced. It also entails building common ground across epistemological word views to strengthen the robustness of implementation research by improving the use of conceptual frameworks, addressing uncertainty and fostering collaboration. Given the complexity of scaling up and sustaining community RMNCH, ensuring that evidence translates into action will require the ongoing brokering of relationships to support the human creativity, scepticism and scaffolding that together build layers of evidence, critical thinking and collaborative learning to effect change.

\section{INTRODUCTION}

Since the Alma-Ata Declaration, community-based approaches have been enshrined by the global health community as central to primary healthcare. Despite this recognition and numerous successful experiences, working with communities is often poorly understood, not sufficiently or appropriately invested in and, in some settings, considered only as an afterthought. While often considered as a disadvantaged geographic location
Summary box

We argue against the hubris of relying on one form or hierarchy of evidence to sustain community programmes at scale.

- Humility in revisiting how we see communities, understand interventions and frame evidence uses, opens up the need for a broader range and bette fit between research questions, designs and types of evidence.

- Implementing and sustaining community programmes at scale must embrace humanity in all its complexity and corresponding research should:

- Use conceptual frameworks that consider the complexity and context embeddedness of interventions

- Explore contradictory or negative evidence and respect each research tradition for its own ways of ensuring confidence in research findings.

- Collaborate with and align expectations among a broader range of stakeholders in evidence gathering, interpretation and use.

or a disenfranchised denomination, communities are also sites of transformation, intrinsically and strategically vital to improving and sustaining health and well-being. Their expertise, capacities and ownership, coupled with support from external actors and resources, can drive innovations and sustain meaningful change essential for overcoming enduring health deficits and disparities. ${ }^{12}$

Evidence supports working with communities as a key foundation for improved reproductive, maternal, newborn and child health (RMNCH). Several systematic reviews, ${ }^{3-7}$ prioritisation exercises ${ }^{89}$ and global recommendations clarify the knowledge base and strengthen research underpinning community-level interventions. These research efforts play an important role in galvanising 
support for effective action for improving community programmes.

These prior evidence initiatives largely focus on the technical content of what must be done, rather than how implementation processes in dynamic and diverse health systems sustain community programmes at scale. ${ }^{10}$ Dominant research paradigms focus on discerning the effects of discrete interventions, yet most practitioners and community members do not implement singular interventions in isolation. At the community level, they must address multiple, at times competing, health needs through various health actions and interventions involving disparate actors, embedded in contested power relations. A range of supportive systems are required to broker community partnerships that embrace this complexity and implementation uncertainty. Considering these needs, we outline ways of enriching our appreciation of implementation realities in which community programmes take place, and ways to strengthen the research foundation to address these realities.

\section{UNDERSTANDING COMMUNITY IMPLEMENTATION REALITIES}

Revisiting how we see communities, how we understand interventions and the corresponding heterogeneity of evidence needs and uses is critical to gaining a better appreciation of community programme implementation realities.

\section{Communities: social systems versus passive beneficiaries}

Challenges in scaling up community health efforts are often argued to be due to incapacity, intransigent behaviours or insufficient and insecure investments. We argue that these are not just a matter of missing inputs or correcting behaviour, but are surface manifestations of the complex nature of many community-based approaches. Characteristics of complex systems include those that involve a large number of diverse elements, that interact dynamically, often in non-linear ways, informed by direct and indirect feedback, in open systems with memory and adaptive capacities. ${ }^{11}$ Many of these interactions are not well explored, yet the effects of community interventions have interactive and intergenerational effects. While individual health outcomes are measured, the trajectory of a family's or community's health for many years is rarely assessed. We expand our evaluation horizons by drawing on the notion of complexity to understand communities as social and political systems; recognising the diversity they embody and the inequalities that mark them; their linkages with other resources and social forces and their ability to learn, promote or resist the social changes within and around them.

While ideally communities are meant to cohere with commonality, or a shared sense of belonging, they also can embody significant ambiguity, heterogeneity, disparity and contestation. ${ }^{12-15}$ Community efforts are often idealised as equitable, but they may ignore, or even at times, abet forces of inequity and marginalisation
Box 1 Examples of how social hierarchies influence community health programmes

- Community health workers may provide less services to community members outside of their kinship ties and female community health workers may face significant gender norms constraining their performance. $^{6768}$

- Caste hierarchies can influence who participates in village health committees and their ability to effectively contribute to health facilities. $^{69}$

- The extent of income inequality and ethnic fractionalisation also affects community social accountability efforts. ${ }^{70}$

- As more interventions are loaded onto community platforms, community health workers may mobilise for more formal recognition, and communities themselves may want more professionalised service providers. ${ }^{71} 72$

- An emphasis on literacy to maintain logbooks and financial compensation for time use may change the profile of community health workers to more educated, male members, with trade-offs related to retention due to competing labour markets. ${ }^{73}$

within communities, which in turn impacts programme outcomes. Attention to how different subgroups within communities may stand to gain or lose differentially due to an intervention is critical (box 1).

Communities are diverse and fluid entities within and across contexts, and their character and ability to act is influenced by their contextual interlinkages to other actors and determinants, over which they may have little control. ${ }^{16-19}$ Stressing the importance of contextual determinants does not mean that communities are helpless victims of contextual factors. ${ }^{20}$ Guided by current learning and past shared experience, community interest, decision-making and ability to participate in health initiatives is dynamic and can vary over time ${ }^{21-23}$ (box 2).

Framing communities as social and political complex systems entails investing more strongly in engagement processes to properly consider multiple community actors and perspectives and the negotiated power

Box 2 Examples of how contextual factors interact with community programmes

- A community volunteer program in Ghana substantially increased newborn care seeking and referral compliance, however poor quality of care at health facilities undercut the credibility of referrals made by community volunteers. ${ }^{74}$

- Successful advocacy by community volunteers in Chattisgarh, India led to improvements in facility care in terms of physician attendance, out-of-pocket payments and malpractice. ${ }^{75}$

- As women's groups mobilise around improving newborn health outcomes, they may also want to act on other issues due to the capacities built and as interests, expectations and needs evolve. ${ }^{76}$

- Once treatment levels for certain conditions such as onchocerciasis reduce the visibility of skin disorders and the experience of blindness in communities, community distributors may have a harder time sustaining adherence than previously when symptoms were common and visible. ${ }^{77}$ 


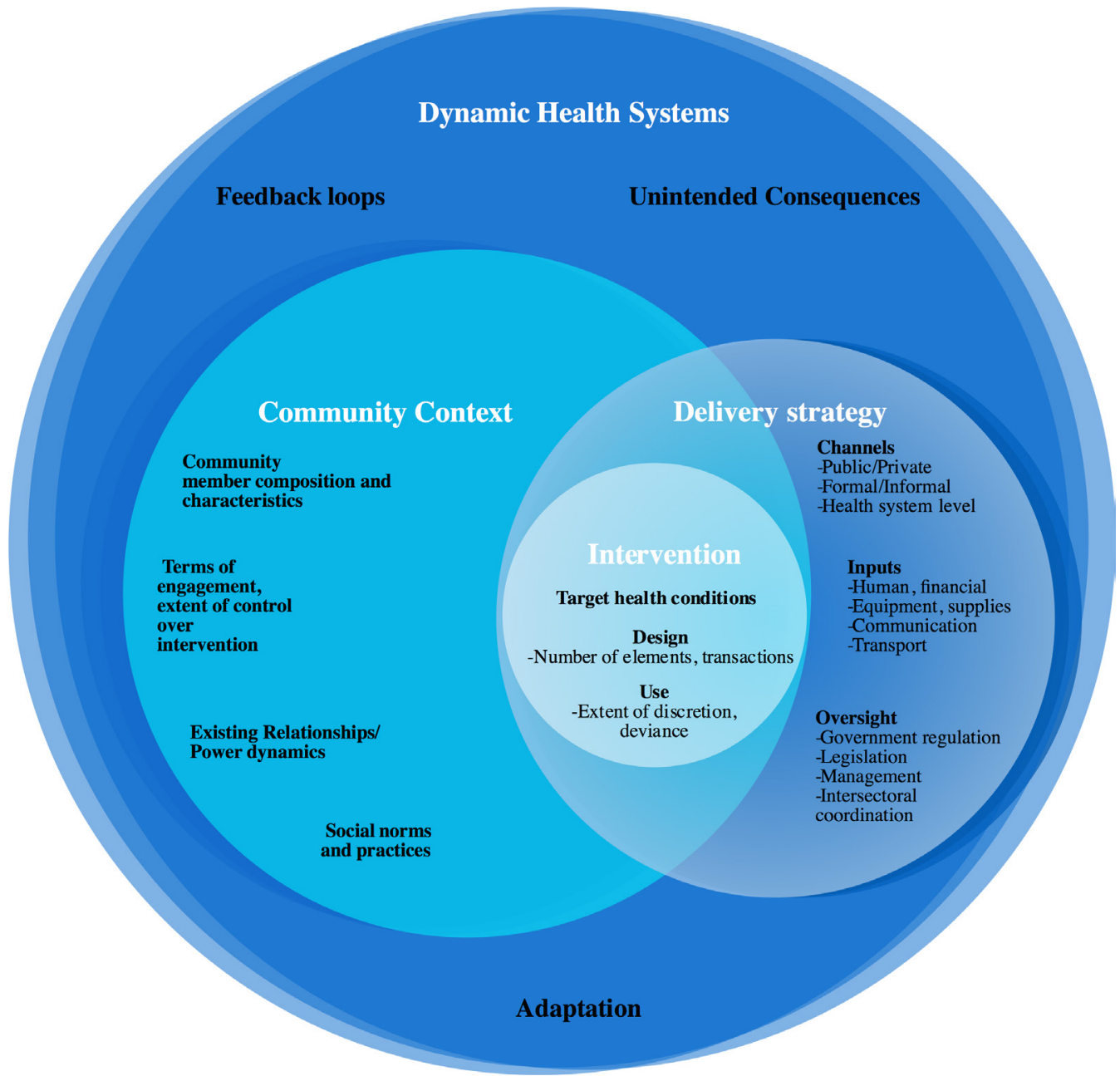

Figure 1 Complexity and context embeddedness of community-based programmes and interventions.

relations between them. Often planned, but not consistently implemented, continuous dialogue and learning mechanisms are required as assumptions underpinning planning and implementation need revisiting, since communities are evolving themselves, adapting to interventions and changing contextual realities. Research initiatives need to invest time into these consultative processes over the course of the project. Throughout transparency, trust and legitimacy among community members and between communities and external actors are essential but neglected characteristics of community-level initiatives. ${ }^{1}$

\section{Interventions: as social processes dynamically evolving with social context}

Alongside the complexity of communities as social systems are the interventions implemented with and by them. Interventions often describe commodities, technologies or actions that have a direct effect on health (eg, oral rehydration salts (ORS) and zinc, rapid diagnostic tests, vaccination). However, they also include community processes involving numerous, diverse actors and interactions with more distal effects on health (eg, promoting awareness of maternal health rights, changing social norms around female genital mutilation/cutting, improving social accountability for better RMNCH services). Once implemented and sustained at scale, interventions are also social processes that evolve and adapt in interaction with dynamic contexts, ${ }^{24-26}$ shaped by different social actors and their intersecting ideologies, relationships, interests, values, routines and resources. ${ }^{23} 27$

One way to discern the social processes involved is to assess their complexity and context embeddedness within dynamic health systems. Numerous typologies exist for classifying interventions by their design characteristics ${ }^{28-30}$ including those that define complexity by the number and diversity of actors involved, and the number and type of interactions they engage in. ${ }^{31} 32$ Drawing on these previous efforts, we provide an initial framework for understanding the complexity and context embeddedness of community interventions by differentiating (a) intervention characteristics, (b) delivery strategies, (c) community contexts and (d) the dynamic health systems within which implementation occurs (figure 1).

We use this framework to contrast the complexity and contextual considerations involved in two examples of community RMNCH interventions: zinc for the management of acute diarrhoea in children 
Table 1 Contrasting contextual complexity of diarrhoea management with zinc and oral rehydration salts (ORS) vs women's groups

\section{Contextual complexity}

\section{Diarrhoea management: zinc and ORS Women's groups}

Intervention characteristics

- Underlying health condition(s) targeted.

- Intervention's design aspects (number of elements and transactions required).

- Intervention's use (extent of discretion and deviance users have in its adoption).
- Severity of acute diarrhoea may vary, as does symptom recognition and disease classification by caregivers.

- Use of ORS does not lessen the stool output or disease severity.

- Recommended course of zinc treatment spans 10-14 days and observed reductions in stool output may take days to be realised.

- User demand and supplier preference for antidiarrhoeals and antibiotics as an alternative remain unaddressed, subverting ORS and zinc health education messages.
- Initial focus on maternal-newborn health encompasses various health conditions and issues, but groups can address community health issues beyond maternal-newborn if prioritised by them.

- Participatory nature of the intervention means that groups can go beyond maternal newborn health.

- Focus and function depends on quality of facilitation and extent of devolved power.

Delivery strategy

- Range of inputs.

- Through what channels.

- With what oversight.
- ORS and zinc as products are fixed, although variations in the taste masking, formulation and packaging may occur.

- Ensuring product quality, availability and distribution is socially complex:

- Zinc can take several days to reduce stool output resulting in users pressuring providers for antidiarrhoeals or other products.

- Zinc dosage sold by private providers may vary based on number of other products prescribed, user resources/ profit thresholds and other factors.
Community context

- Community member composition and characteristics.

- Their terms of engagement and control over the intervention.

- Existing power dynamics and relationships.

- Current social norms and practices.

- The contestation of social change in non-linear ways.
While power relations exist between caregivers of young children, other family members and local health, their social relations are unlikely to alter the nature of ORS and zinc as a standardised product. However, private providers will market products as being different given the need to differentiate what can be accessed for free from the public sector.
- Targets a broad group of stakeholders and needs to engage with power relations between them, particularly when marginalised groups begin to work on changing social norms and practices that contravene women's health.

- Adaptations include self-selection in and out of the group, frequency of meetings, continuity and representativeness of group leadership.

- Initial actions and reactions or feedback loops key to building trust, legitimacy and social capital for further actions. Contestation by conservative community gatekeepers can undermine initial actions particularly if gains are not visible. and participatory action women's groups (table 1). While zinc and ORS as commodities may not change, their interpretations and use by caregivers and providers in varied settings are not always as simple as anticipated. Nonetheless, the comparative complexity of women's groups generally entails a larger number of elements that interact in potentially more unpredictable ways. 
Understanding the complexities and context embeddedness of community interventions as social processes is necessary because issues of scale and sustainability are not about replicating fixed, stable interventions. Community RMNCH is inherently about how diverse actors interpret, respond and adapt to the social changes brokered and unleashed by interventions and programmes. We therefore need to better understand the fluidity of interventions because effects cannot be assumed to be universal or stable over time. This entails continuous assessment of how diverse stakeholders view and dynamically respond to interventions, along with holistic theories or pathways of effect as the boundaries and pathways of an intervention are more varied and more porous than initially anticipated. This has implications for facilitating implementation, and for the varied evaluation needs that arise..$^{2633}$

\section{Evidence: heterogeneity versus hierarchy of needs and uses}

In instances of high complexity, adaptation is a critical, ongoing process that needs to be explored intentionally, as contexts, actors and interventions themselves change due to feedback effects. ${ }^{30} 323435$ Such an exploration may change understanding of if and how the intervention works, as well as the very nature and boundaries of the intervention itself. In such contexts, efforts to achieve fidelity to the original intervention design may not be appropriate or may even be counterproductive. ${ }^{27} 36$ The question 'does the intervention work?', supported by mode 1 science that is investigator-driven, discovery oriented research conforming to 'scaling up known solutions using implementation by edict ${ }^{, 37}$ may distract from other research needs.

Generating evidence that supports sustaining complex community interventions and programmes at scale is also about understanding 'how does the intervention evolve to work with different actors and contexts which are dynamically interacting with one another?' This requires mode 2 research that is coproduced by researchers and implementers and therefore supports local capacity to experiment and innovate based on learning about what works to address specific problems in a particular context and mobilising commitments to implement. ${ }^{26} 38$ Evidence that supports implementation may focus on how to learn from error and aide local problem solving and critical thinking based on analytical generalisation, rather than trying to find universal solutions that are then subsequently adapted to local contexts later.

Multiple reviews and commentaries on scaling up that have concluded that there is no blue print plan that is applicable to all contexts. ${ }^{104041}$ Critical factors supporting scale up include understanding and modifying the nature of the intervention-with the engagement of multiple stakeholders-supported by data and dialogue that address context-specific needs and further innovation. ${ }^{42} 43$ Ownership that ensures relevance and fit is vital at multiple levels of the health system. Research should directly support critical thinking and learning that ensures that interventions are addressing the right needs for the right populations at the right times.

Furthermore, as evidence is socially constructed, it reflects how questions, research methodologies, values and social relationships combine to generate it. ${ }^{134}$ Because it reflects power relations, evidence may not reflect the perspectives of all stakeholders, particularly those at community level. ${ }^{13}$ Research prioritisation exercises for integrated community case management for sick children (iCCM) have shown that research questions deemed important by national and regional actors were different from those based in the headquarters of global health agencies. ${ }^{9}$ More in-depth analysis showed that while international actors were concerned with evidence from effectiveness studies, national actors drew on national monitoring data and local studies to answer questions related to feasibility and fit. ${ }^{45}$ It is imperative that existing biases in how global agendas for research in community $\mathrm{RMNCH}$ are set are recognised and addressed.

When considering issues of implementation, scale and sustainability, rather than constrain learning to a hierarchy of evidence, we need to match the varied needs arising from the diverse types of learning and engagement of key stakeholders whose capacity is being built to support and sustain further innovation and implementation over time. ${ }^{27} 46$ This liberates us to consider a broader range of research questions, ${ }^{47}$ but also to broaden the types of stakeholders engaged in research and the terms of that engagement. ${ }^{48}$

\section{BUILDING COMMON GROUND ACROSS EVIDENCE FRONTIERS}

The call to expand evidence strategies has been heightened by the increasing emphasis on implementation research and delivery science. ${ }^{49} 50$ Implementation research is multidisciplinary, drawing from public policy analysis and more recent efforts to improve clinical and public health practice. Implementation research aims to inquire into "the act of carrying an intervention into effect' and involves addressing implementation barriers in real-world settings rather than controlled settings. ${ }^{51}$ Furthermore, Edwards and Barker ${ }^{52}$ argue that this type of research is anchored by its consideration of context, specifically how context 'shapes and interacts with interventions, and how interventions are modified/adapted by patients, providers, organisations and communities in response to shifting contextual circumstances'. A focus on how implementation effects the actors involved, their interactions, mindsets, relationships, resources and discretionary power is critical. ${ }^{275354}$

A range of study designs and methods have been recommended to advance implementation research ${ }^{51}$ with very different world views. Positivist epistemologies, perceive facts to be objectively verified and universal, contrast with relativist worldviews, where social realities are more fluid and dynamic, varying by context and interpreted viewpoints. Despite these differences, it is the 
nature of the research problem and question that drives the call for whether and how to pragmatically combine these different epistemological approaches to evidence. ${ }^{55}$ Common elements for ensuring robustness of research need to be strengthened for future investments in evidence for community programmes. As detailed in the next sections, these include better mapping and building of conceptual frameworks to interpret evidence and embrace complexity and context rather than controlling or adjusting for it; using multiple data points to understand phenomena and search for plausible alternative explanations and the terms of engagement for diverse stakeholders.

\section{Conceptual frameworks that embrace complexity and context}

The universal ambitions of impact evaluations and the local relevance and ownership of participatory, qualitative or mixed methods studies, are both strengthened by mapping out pathways of change supported by community interventions. Conceptual frameworks, logic models and theories of change are all different breeds, but they belong in the same species of maps that can build a deeper understanding of an intervention, as well as foster dialogue and improved governance of the diverse actors involved in implementation.

Conceptual frameworks can clarify the intended goal of an intervention and anticipate the factors that lead towards that goal in distinct contexts, while also providing a broader theoretical and contextual understanding for a programme's approach. For example, efforts to strengthen village health committees tend to focus on tangible inputs and outputs (training, guidelines, number of meetings held). While these are important, a broader conceptualisation considers several contextual factors-including community and health facility staff awareness, trust, perception of benefits, resources and social inequalities. These are dynamic and malleable in nature depending on the nature of broader structural elements (role of health administration, legislative reforms, markets, history of social movements, etc).$^{20} 56$

By clarifying assumptions, identifying hypotheses about pathways of effects that need to be tested and more realistically documenting the duration of implementation required to achieve desired outcomes, conceptual frameworks can help to moderate expectations among stakeholders. For example, mapping out the complex pathways in which community scorecards effect change in communities and local health facilities, may help clarify reasonable expectations and timeframes. In doing so, frameworks can help to focus the purpose of evaluations, and clarify their limitations in terms of what can be changed and measured.

Conceptualised as 'living tools', frameworks reflect both an end product and process. Ideally, they are developed through a consultative process, and revised throughout the life of a project in response to early monitoring and evaluation data, changes in assumptions and/or programme design/implementation. Rather than a one-time investment, they should serve as a tool to support reflexivity and mark learning in intervention design and evaluation on an ongoing basis. Developing and revising conceptual frameworks can open up new lines of investigation and broaden the scope of what is relevant in understanding how the intervention works and why, particularly when new or contradictory information needs interpretation.

\section{Contrasting data and counterfactuals}

Experimental designs focus on narrowing uncertainty about effects through the use of counterfactuals and controlled implementation. In implementation research, this use of counterfactuals or comparisons should change with evolving research needs. For example, when focusing on efficacy and effectiveness, home-based treatment of neonatal sepsis by an externally supported community health worker (CHW) may be compared with the standard of care provided by a government-employed higher-level health worker. When focusing on delivery at scale, results will be more relevant when compared with a government-supported CHW that undertakes the same tasks, particularly when doing so in an integrated manner with other interventions, and working in a system with suboptimal supervision and fewer health system supports.

While the term 'counterfactual' is associated with experimental designs that demonstrate causality, its purpose of ruling out rival explanations can also be pursued for other types of research questions through a variety of means across research traditions. For example, triangulation is the process of 'looking for patterns of convergence and divergence by comparing results across multiple sources of evidence, ${ }^{55}$ whether across interviews capturing diverse stakeholder viewpoints; across different forms of data or different researchers. The purpose is to better understand the study realities, and this includes looking for negative evidence that contradicts assumptions made about the intervention or examining case studies that present divergent experiences of the intervention.

Research communities, including journals and research donors, need to value and encourage the publication of negative findings and unintended consequences, along with the reflections of what could have been done differently. Investing time into a robust conceptual framework helps ensure that additional data points for triangulation and further exploration of contradictory or divergent examples, results in a more comprehensive, contextualised and nuanced picture of the intervention. Expectations of quick answers from rapid qualitative assessments bely the time required for more in-depth ethnographic methods, which are more able to understand context, power relations and changing motivations underlining community interventions over time. ${ }^{23}$

Research is not just about formally confirming donor or manager tacit knowledge, but also about exploring alternative framings of the problems examined, supporting fair dealing of the range of data sources and perspectives 
available, to develop trustworthy findings. ${ }^{57}$ Depending on the research question and study design, confidence in research is not limited to statistical comparisons or large sample sizes. It can also arise by fostering long-term engagement and relationship building with a diversity of stakeholders.

\section{Collaboration as the basis for evidence use and generation}

There is a well-recognised gap between the production of research evidence and its translation into policies, programmes and practices, with processes for evidence generation and dissemination lagging behind political and management decision-making timelines. ${ }^{58}$ Beyond issues of timing, availability and relevance, ${ }^{58} 59$ evidence use, research uptake or knowledge translation is increasingly understood to be a multifaceted, iterative process imbued with power relations and systems dynamics that often defy or circumvent the traditional 'pipeline' theory of research-based evidence directly influencing policy and practice. ${ }^{6061}$ In the instance of iCCM policy, diffusion occurred through a combination of learning, coercion and socialisation with international agencies treading a fine line between evidence brokers and policy advocates. ${ }^{62}$ In health systems, personal relationships between researchers and decision-makers, organisational embeddedness and credible reputations can be critical factors in knowledge translation. 585963

The kinds of relations needed are not simply political or personal, but also entail different actors bringing a spirit of collaboration and mutual learning, and building communities of knowledge. ${ }^{59} 64$ This entails supporting local capacity-building and creation of local forums, which routinely review evidence and implementation experiences at different levels of the health system. While learning communities and forms of embedded research encompass experts, policy makers or providers, experiences related to community participation illustrate key principles underlying such engagement. ${ }^{65}$

Community participation in evidence generation requires a significant shift in the approach that is taken to conduct research..$^{15}$ Expertise and power are shared, multiple perspectives and types of knowledge are valued ${ }^{45}$ and a partnership between researchers and communities supports iterative successive stages of learning and action.

Despite its potential, several factors make community engagement challenging in research and evaluation. Some members or groups may refuse to participate or may only engage minimally or late in the research process, affecting representativeness. ${ }^{13}$ Participatory methods also take time to ensure a comprehensive understanding of the community experience and build collective agreement on actions to be taken. ${ }^{156}$ Researchers may also struggle with the dual identity of academic and facilitator in participatory research, and while these dual roles may turn out valuable for all actors involved, they entail additional competencies among researchers to effectively hold such a facilitative role. ${ }^{15}$ Finally, communities may develop expectations of researchers or their roles in the research process that do not align with those of the researchers, and derived learnings are not always the publishable findings that are sought by researchers. ${ }^{66}$

While numerous methods and tools are part of the repertoire of participatory approaches, what these challenges indicate is that an essential element are the principles of engagement underpinning them. Planning and review processes that support the rethinking and cocreation of the roles of researchers and communities may prevent or help navigate these challenges as they arise. ${ }^{15}$ Mechanisms that facilitate engagement need to be identified collaboratively so that they address the power relations and barriers that may continue to inhibit participation of marginalised groups. Clarification of community needs, expectations and rights needs to be communicated and negotiated clearly to sustain trust. In this way, principles of participatory research that aim to ensure that implementers and researchers remain or become accountable to the communities in which they work ${ }^{154}$ are relevant to consider for other types of research and programming aiming to improve community health. Fundamentally, none of these methods and tools will be effective without heightened awareness and self-reflection of all stakeholders, particularly researchers and donors. Audits that reveal potential biases in existing research funding flows are critical to aid self-correction.

\section{CONCLUSION}

Considering the challenges of sustaining complex community health systems at scale, engaging disparate actors across diverse and dynamic contexts, evidence is vital to strengthening its foundation. Efforts to strengthen evidence must guard against the hubris of relying on a single approach to evidence to answer the range of questions that community programmes will face. We need a broader evidence agenda, guided by the fit between research designs, research questions of varied types, which arise from involving diverse stakeholders engaged with improving and sustaining community programme implementation at scale.

Ensuring that evidence translates into action will require humility in understanding the heterogeneity of evidence needs, the dynamic nature of community contexts and the brokering of relationships that are key to supporting the scepticism and scaffolding that together build layers of evidence, critical thinking and collaborative learning to effect change. In building capacities to be responsive to the dynamic adaptations required to ensure effective community programmes across diverse and disparate contexts, such approaches to evidence and learning must embrace humanity in all its creativity and complexity.

Glossary of terms included in supplementary file 1 .

Acknowledgements The authors are grateful to the two blind peer reviewers, as well as review comments provided by Nazo Kureshy, Melanie Morrow, Henry Perry, Jerome Pfaffmann Zambruni, Joseph Petraglia, Susan Rifkin, Gail Snetro and Rajani Ved during the drafting process. The authors also appreciate the feedback provided 
by meeting participants convened by the Maternal and Child Survival Program in Washington, District of Columbia, USA and by those convened by Lucy Gilson at the University of Cape Town, South Africa.

Contributors ASG and AEL led the review with MS and AM with inputs from ES and ES. AG drafted the paper with inputs from all other coauthors. All authors reviewed and approved the last version of this article.

Funding This article was initially made possible by the generous support of the American people through the US Agency for International Development, under the terms of the Cooperative Agreement AID-OAA-A-14-00028. ASG was subsequently supported by the South African Research Chair's Initiative of the Department of Science and Technology and National Research Foundation of South Africa (grant no 82769).

Disclaimer The contents are the responsibility of the authors and do not necessarily reflect the views of USAID or the US Government. Any opinion, finding and conclusion or recommendation expressed in this material is that of the author and the NRF does not accept any liability in this regard.

Competing interests None declared.

Patient consent Not required.

Provenance and peer review Not commissioned; externally peer reviewed.

Data sharing statement № additional data are available.

Open access This is an open access article distributed in accordance with the Creative Commons Attribution Non Commercial (CC BY-NC 4.0) license, which permits others to distribute, remix, adapt, build upon this work non-commercially, and license their derivative works on different terms, provided the original work is properly cited and the use is non-commercial. See: http://creativecommons.org/ licenses/by-nc/4.0/

C) Article author(s) (or their employer(s) unless otherwise stated in the text of the article) 2018. All rights reserved. No commercial use is permitted unless otherwise expressly granted.

\section{REFERENCES}

1. George AS, Mehra V, Scott K, et al. Community participation in health systems research: a systematic review assessing the state of research, the nature of interventions involved and the features of engagement with communities. PLoS One 2015;10:e0141091-25.

2. George AS, Scott K, Mehra V, et al. Synergies, strengths and challenges: findings on community capability from a systematic health systems research literature review. BMC Health Serv Res 2016;16:623.

3. Bhutta ZA, Darmstadt GL, Hasan BS, et al. Community-based interventions for improving perinatal and neonatal health outcomes in developing countries: a review of the evidence. Pediatrics 2005;115(Suppl):519-617.

4. Cornish F, Priego-Hernandez J, Campbell C, et al. The impact of community mobilisation on HIV prevention in middle and low income countries: a systematic review and critique. AIDS Behav 2014;18:2110-34.

5. Christopher JB, Le May A, Lewin S, et al. Thirty years after AlmaAta: a systematic review of the impact of community health workers delivering curative interventions against malaria, pneumonia and diarrhoea on child mortality and morbidity in sub-Saharan Africa. Hum Resour Health 2011;9:1-11.

6. Perry H. Care groups: experience and evidence. 2014.

7. Rifkin SB. Examining the links between community participation and health outcomes: a review of the literature. Health Policy Plan 2014;29(Suppl 2):ii98-106.

8. George A, Young M, Bang A, et al. Setting implementation research priorities to reduce preterm births and stillbirths at the community level. PLoS Med 2011;8:e1000380-8.

9. Wazny K, Sadruddin S, Zipursky A, et al. Setting global research priorities for integrated community case management (iCCM): Results from a CHNRI (Child Health and Nutrition Research Initiative) exercise. J Glob Health 2014;4:1-10.

10. McCoy D, Storeng K, Filippi V, et al. Maternal, neonatal and child health interventions and services: moving from knowledge of what works to systems that deliver. Int Health 2010;2:87-98.

11. Cilliers P. Complexity, deconstruction and relativism. Theory, Culture \& Society 2005;22:255-67.

12. Jewkes R, Murcott A. Meanings of community. Soc Sci Med 1996;43:555-63.
13. Truman C, Raine P. Involving users in evaluation: the social relations of user participation in health research. Crit Public Health 2001;11:215-29.

14. Chiu LF. Engaging communities in health intervention research/ practice. Crit Public Health 2008;18:151-9.

15. Pohl C, Rist S, Zimmermann A, et al. Researchers' roles in knowledge co-production: experience from sustainability research in Kenya, Switzerland, Bolivia and Nepal. Science and Public Policy 2010;37:267-81.

16. Kenny A, Hyett N, Sawtell J, et al. Community participation in rural health: a scoping review. BMC Health Serv Res 2013;13:1-8.

17. Kenny A, Farmer J, Dickson-Swift V, et al. Community participation for rural health: a review of challenges. Health Expectations 2015;18:1906-17.

18. Atkinson JA, Vallely A, Fitzgerald $L$, et al. The architecture and effect of participation: a systematic review of community participation for communicable disease control and elimination. Implications for malaria elimination. Malar J 2011;10:225-33.

19. Farnsworth SK, Böse K, Fajobi O, et al. Community engagement to enhance child survival and early development in low- and middle-income countries: an evidence review. J Health Commun 2014;19(Suppl 1):67-88.

20. George A, Scott K, Garimella S, et al. Anchoring contextual analysis in health policy and systems research: A narrative review of contextual factors influencing health committees in low and middle income countries. Soc Sci Med 2015;133:159-67.

21. Moser C, Sollis P. Did the project fail? A community perspective on a participatory primary health care project in Ecuador. Dev Pract 1991;1:19-33.

22. Ndekha A, Hansen EH, Mølgaard P, et al. Community participation as an interactive learning process: experiences from a schistosomiasis control project in Zimbabwe. Acta Trop 2003:85:325-38

23. Evans $\mathrm{C}$, Lambert $\mathrm{H}$. Implementing community interventions for HIV prevention: insights from project ethnography. Soc Sci Med 2008;66:467-78.

24. Pawson R, Tilley N. Realist evaluation. 2004:1-36.

25. Bodstein R. The complexity of the discussion on effectiveness and evidence in health promotion practices. Promot Educ 2007;(Suppl 1):16-20.

26. Chambers DA, Glasgow RE, Stange KC. The dynamic sustainability framework: addressing the paradox of sustainment amid ongoing change. Implement Sci 2013;8:1-11.

27. Hawe P. Lessons from complex interventions to improve health Annu Rev Public Health 2015;36:307-23.

28. Gericke CA, Kurowski C, Ranson MK, et al. Intervention complexity-a conceptual framework to inform priority-setting in health. Bull World Health Organ 2005;83:285-93.

29. Craig P, Dieppe P, Macintyre S, et al. Developing and evaluating complex interventions: the new Medical Research Council guidance. BMJ 2008;337:a1655-6.

30. Woolcock M. Using case studies to explore the external validity of "complex" development interventions. Helsinki, Finland: UNUWIDER, 2013:1-22.

31. Geyer R, Rihani S. Complexity and public policy. Oxon, OX: Routledge, 2010

32. Sarriot E, Kouletio M. Community health systems as complex adaptive systems: ontology and praxis lessons from an urban health experience with demonstrated sustainability. Syst Pract Action Res 2014.

33. Rychetnik L, Frommer M, Hawe P, et al. Criteria for evaluating evidence on public health interventions. J Epidemiol Community Health 2002;56:119-27.

34. Rittel HWJ, Webber MM. Dilemmas in a general theory of planning. Policy Sci 1973;4:155-69.

35. Sarriot EG, Kouletio M, Jahan DS, et al. Advancing the application of systems thinking in health: sustainability evaluation as learning and sense-making in a complex urban health system in Northern Bangladesh. Health Res Policy Syst 2014;12:45

36. Pérez $\mathrm{D}$, Lefèvre $\mathrm{P}$, Castro $\mathrm{M}$, et al. Process-oriented fidelity research assists in evaluation, adjustment and scaling-up of communitybased interventions. Health Policy Plan 2011;26:413-22.

37. Andrews M, Pritchett L, Woolcock M. Escaping capability traps through problem driven iterative adaptation (PDIA). 2012. Helsinki, Finland. Report No: 64.

38. Pritchett L, Salimah S, Hammer J. It's all about MeE: using structured experiential learning ("e") to Crawl the design space. Washington, D.C: Center for Global Development, 2013:1-55.

39. Lomas J. Decision support: a new approach to making the best healthcare management and policy choices. Healthc $Q$ 2007:10:16-18. 
40. Spicer N, Bhattacharya D, Dimka R, et al. 'Scaling-up is a craft not a science': Catalysing scale-up of health innovations in Ethiopia, India and Nigeria. Soc Sci Med 2014;121:30-8.

41. Nyamtema AS, Urassa DP, van Roosmalen J. Maternal health interventions in resource limited countries: a systematic review of packages, impacts and factors for change. BMC Pregnancy Childbirth 2011;11:30.

42. Subramanian S, Naimoli J, Matsubayashi T, et al. Do we have the right models for scaling up health services to achieve the Millennium Development Goals? BMC Health Serv Res 2011;11:1-10.

43. Yamey G. Scaling up global health interventions: a proposed framework for success. PLoS Med 2011;8:e1001049-6.

44. Springett J. Appropriate approaches to the evaluation of health promotion. Crit Public Health 2001;11:139-51.

45. Rodríguez DC, Shearer J, Mariano AR, et al. Evidence-informed policymaking in practice: country-level examples of use of evidence for iCCM policy. Health Policy Plan 2015;30(Suppl 2):ii36-ii45.

46. Ottoson JM, Green LW. Community outreach: from measuring the difference to making a difference with health information. J Med Libr Assoc 2005;93(Suppl):S49-56.

47. Petticrew M, Roberts H. Evidence, hierarchies, and typologies: horses for courses. J Epidemiol Community Health 2003;57:527-9.

48. Chambers R. Paradigms, poverty and adaptive pluralism. Brighton, United Kingdom: IDS Working Papers, 2010.

49. Alliance for Health Policy and Systems Research, The World Bank, United States Agency for International Development. Statement on advancing implementation research and delivery science. Cape Town, South Africa: Alliance for Health Policy and Systems Research, 2014.

50. Kim JY, Farmer P, Porter ME. Redefining global health-care delivery. Lancet 2013;382:1060-9.

51. Peters $\mathrm{DH}$, Adam $\mathrm{T}$, Alonge $\mathrm{O}$, et al. Implementation research: what it is and how to do it. BMJ 2013;347:f6753.

52. Edwards N, Barker PM. The importance of context in implementation research. J Acquir Immune Defic Syndr 2014;67(Suppl 2):S157-62.

53. Erasmus E, Orgill M, Schneider $\mathrm{H}$, et al. Mapping the existing body of health policy implementation research in lower income settings: what is covered and what are the gaps? Health Policy Plan 2014;29(Suppl 3):iii35-50.

54. Gilson L, Schneider H, Orgill M. Practice and power: a review and interpretive synthesis focused on the exercise of discretionary power in policy implementation by front-line providers and managers. Health Policy Plan 2014;29(Suppl 3):iii51-69.

55. Gilson L, Hanson K, Sheikh K, et al. Building the field of health policy and systems research: social science matters. PLoS Med 2011;8:e1001079.

56. McCoy DC, Hall JA, Ridge M. A systematic review of the literature for evidence on health facility committees in low- and middleincome countries. Health Policy Plan 2012;27:449-66.

57. Sheikh K, George A, Gilson L. People-centred science: strengthening the practice of health policy and systems research. Health Res Policy Syst 2014;12:19.

58. Humphries S, Stafinski T, Mumtaz Z, et al. Barriers and facilitators to evidence-use in program management: a systematic review of the literature. BMC Health Serv Res 2014;14:1-15.

59. Oliver K, Innvar S, Lorenc T, et al. A systematic review of barriers to and facilitators of the use of evidence by policymakers. BMC Health Serv Res 2014;14:1-12.

60. Greenhalgh T, Wieringa S. Is it time to drop the 'knowledge translation' metaphor? A critical literature review. J R Soc Med 2011;104:501-9.
61. Best A, Terpstra JL, Moor G, et al. Building knowledge integration systems for evidence-informed decisions. J Health Organ Manag 2009;23:627-41.

62. Bennett S, Dalglish SL, Juma PA, et al. Altogether now... understanding the role of international organizations in iCCM policy transfer. Health Policy Plan 2015;30(Suppl 2):ii26-35.

63. Koon AD, Rao KD, Tran NT, et al. Embedding health policy and systems research into decision-making processes in low- and middle-income countries. Health Res Policy Syst 2013;11:1-9.

64. Oliver K, Lorenc T, Innvær S. New directions in evidence-based policy research: a critical analysis of the literature. Health Res Policy Syst 2014;12:1-11.

65. Loewenson R, Laurell AC, Hogstedt C, et al. Participatory action research in health systems: a methods reader. Harare, Zimbabwe: TARSC, AHPSR, WHO, IDRC Canada, EQUINET, 2014.

66. Montoya MJ, Kent EE. Dialogical action: moving from communitybased to community-driven participatory research. Qual Health Res 2011;21:1000-11.

67. Clemmons L, Amazigo UV, Bissek AC, et al. Gender issues in the community-directed treatment with ivermectin (CDTI) of the African Programme for Onchocerciasis Control (APOC). Ann Trop Med Parasitol 2002;96(Suppl 1):S59-74.

68. Mumtaz Z, Salway S, Nykiforuk C, et al. The role of social geography on Lady Health Workers' mobility and effectiveness in Pakistan. Soc Sci Med 2013;91:48-57.

69. Bishai D, Niessen LW, Shrestha M. Local governance and community financing of primary care: evidence from Nepal. Health Policy Plan 2002;17:202-6.

70. Björkman M, Svensson J. When is community-based monitoring effective? Evidence from a randomized experiment in primary health in Uganda. J Eur Econ Assoc 2010;8:571-81.

71. George A, Rodríguez DC, Rasanathan K, et al. iCCM policy analysis: strategic contributions to understanding its character, design and scale up in sub-Saharan Africa. Health Policy Plan 2015;30(Suppl 2):ii3-11.

72. Callaghan-Koru JA, Hyder AA, George A, et al. Health workers' and managers' perceptions of the integrated community case management program for childhood illness in Malawi: the importance of expanding access to child health services. Am J Trop Med Hyg 2012;87(5 Suppl):61-8.

73. Chilundo BG, Cliff JL, Mariano AR, et al. Relaunch of the official community health worker programme in Mozambique: is there a sustainable basis for iCCM policy? Health Policy Plan 2015;30(Suppl 2):ii54-64.

74. Ansah Manu A, ten Asbroek A, Soremekun S, et al. Evaluating the implementation of community volunteer assessment and referral of sick babies: lessons learned from the Ghana Newhints home visits cluster randomized controlled trial. Health Policy Plan 2014;29(Suppl 2):ii114-27.

75. Nandi S, Schneider H. Addressing the social determinants of health: a case study from the Mitanin (community health worker) programme in India. Health Policy Plan 2014;29(Suppl 2):ii71-81

76 WHO, 2015b. WHO Recommendations on Health Promotion Interventions for Maternal and Newborn Health. Geneva Switzerland: World Health Organization, 2015.

77 Brieger WR, Okeibunor JC, Abiose AO, et al. Characteristics of persons who complied with and failed to comply with annual ivermectin treatment. Trop Med Int Health 2012;17:920-30. 